\title{
Formas da apresentação: espaço, imagem, invisibilidades ${ }^{1}$
}

Resumo

Partindo de trabalhos artísticos pessoais e situando-se no contexto da arte contemporânea, este estudo desenvolve uma reflexão acerca do uso, da experiência e da noção de invisibilidade num processo de criação em artes plásticas e visuais. Como a invisibilidade pode impulsionar uma poética relacionando a apresentação, o espaço e a imagem? Como a inserção da invisibilidade num dado contexto poderia problematizar e criar outras situações e sentidos para a apresentação?

Palavras-chave:

Formas da apresentação, imagem, invisibilidade 


\title{
Presentation forms: place, image, invisibility
}

\author{
HÉLIO FERVENZA
}

Keywords: Presentation forms, image, invisibility

\begin{abstract}
Started from personal artwork and located in contemporary art context, this research develops a thought about the use, the experience and the notion of invisibility in a creation process in plastic and visual arts. How invisibility can stimulate a poetic related to presentation, place and image? How the insertion of invisibility in certain context could discuss and create other situations and senses to presentation?
\end{abstract}




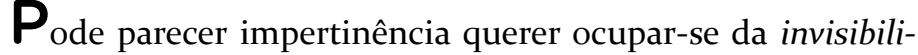
dade quando parte significativa do contexto, das estratégias e discursividades relacionadas à criação e a apresentação das artes visuais contemporâneas mostrarem-se mais preocupadas com a visibilidade e com tudo aquilo que possa estar aí relacionado. Pode parecer estranho e ilógico querer tratar da invisibilidade dentro de uma área cujo foco de interesse é explicitado por seu nome: artes visuais. Entretanto, é justamente isso que por diversas ocasiões tem me ocupado já há alguns anos: criar e pensar essas invisibilidades. E é precisamente isso que gostaria de abordar aqui ${ }^{2}$. O problema talvez não seja exatamente o da invisibilidade em si, pois ela é justamente componente do visível (não há visibilidade sem invisibilidade), mas constatar hoje em dia sua negação através da enorme proliferação de visibilidades, e por decorrência, a ênfase na sua perda de sentido.

O que seria então na atualidade introduzir a invisibilidade num processo de criação em artes plásticas? Como a invisibilidade pode impulsionar uma poética relacionando a apresentação, o espaço e a imagem? Como a inserção da invisibilidade num dado contexto poderia criar novas situações de apresentação?

Como artista e pesquisador, realizei trabalhos tais como A dúvida 3 , Objetos mentais ${ }^{4}$, Oásis, País do futuro ${ }^{5}$, Degelo $^{6}$, os quais possuem algumas características em comum, entre as quais, a de se ocuparem com invisíveis, de indicá-los e de enunciá-los a partir de sua constituição. Esses trabalhos apontam, indicam uma invisibilidade, são geradores de espaços invisíveis.

A dúvida, por exemplo, é o nome de uma proposta de exposição, com características de intervenção, realizada em 2004 na FotoGaleria em Porto Alegre, no período do encerramento definitivo de atividades desse espaço que durante alguns anos dedicou-se a mostras de fotografia. A FotoGaleria iria fechar 
suas portas e não teríamos mais exposições, nem fotografias ali. Não teríamos mais imagens, mas era justamente essa ausência que viria se fazer sentir. Aquilo que não veríamos mais produziria um efeito em nós. $\mathrm{O}$ fato delas não estarem mais visíveis é que gerava um sentimento, de perda talvez, de desânimo, de conflito e insatisfação face às dificuldades crônicas da cidade. Essas circunstâncias impulsionaram a concepção da proposta. Era uma ocasião que se apresentava como propícia para abordar questões relativas à imagem, além é claro, daquelas mais urgentes naquele momento preciso, ou seja, relacionadas com a precariedade dos espaços para atividades artísticas e mostras de arte. O que me levou a considerar também, as dificuldades e a precariedade na produção de uma voz, ou as dificuldades para enunciar um pensamento outro, e por decorrência, a de enunciar qualquer pensamento.

Figura 1 A dúvida, FotoGaleria, Porto Alegre, 2004.

Vista de parte do entorno e do portão de acesso da galeria com texto em vinil adesivo.

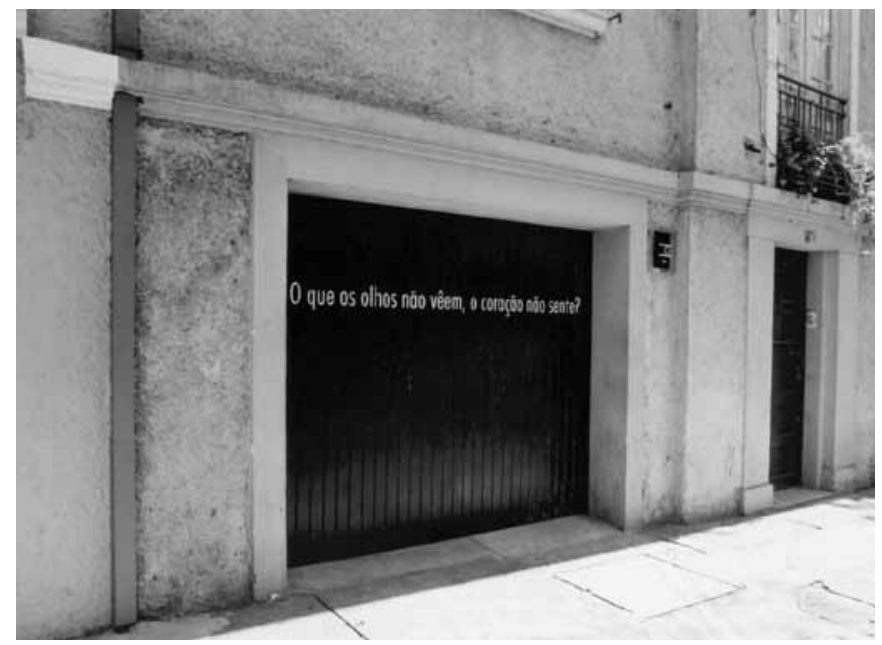

Figura 2

A dúvida, FotoGaleria, Porto Alegre, 2004. Vista do portão de acesso da galeria com texto em vinil adesivo.

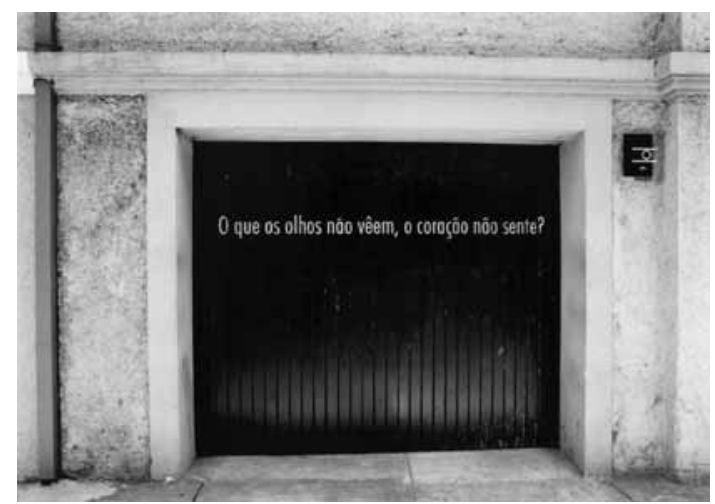


A dúvida consistia na reprodução de uma imagem da fachada da galeria, acompanhada da frase "O que os olhos não vêem, o coração não sente?” impresso com plotter sobre lona vinílica nas dimensões desse espaço. Colocada de tal forma na entrada, a imagem formava uma barreira material e impossibilitava adentrar no espaço interno da galeria. No portão de acesso foi colocada a mesma frase, escrita com letras em vinil adesivo. Essas duas situações alternavam-se.

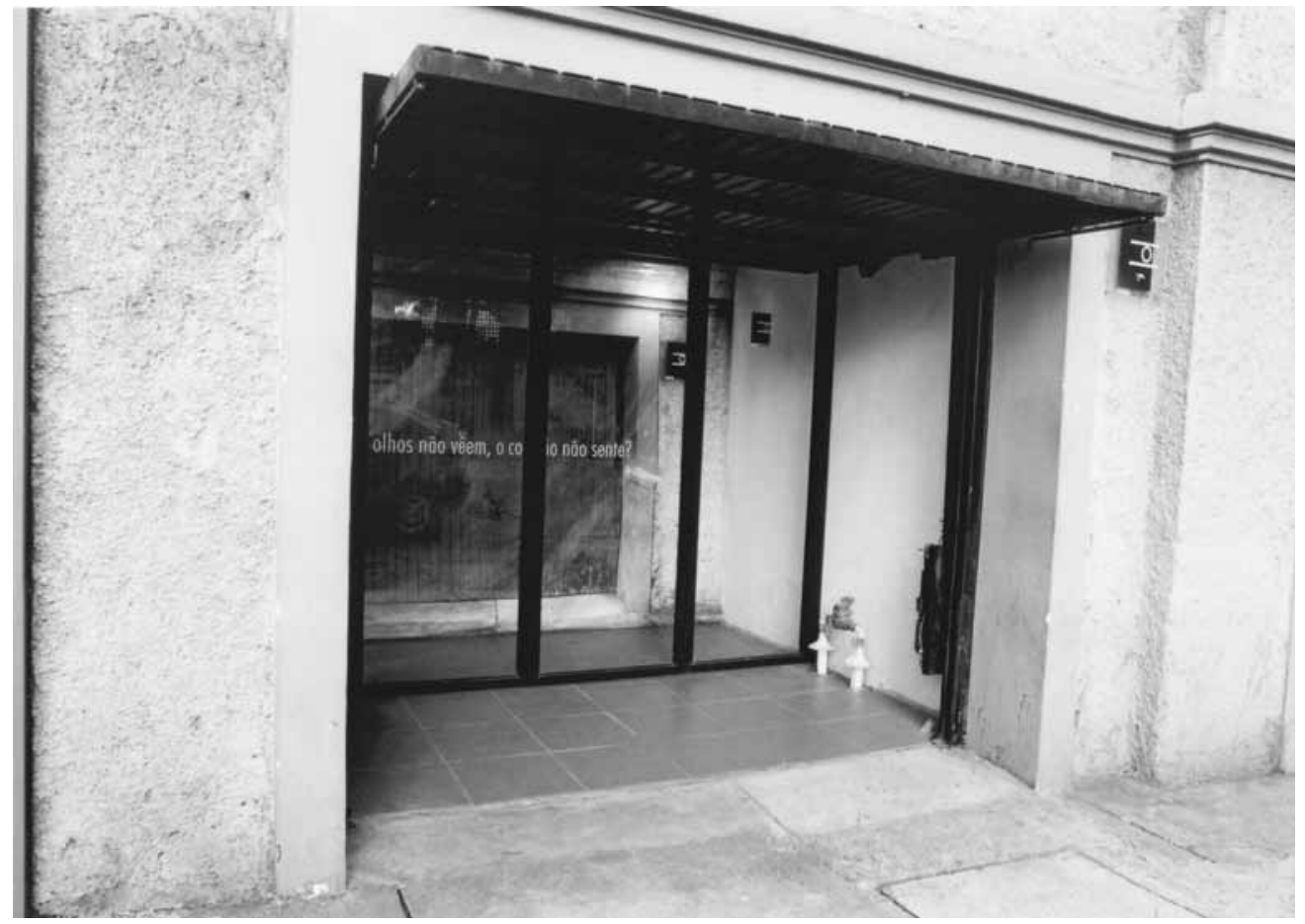

A dúvida trabalhava com a noção de fechamento, utilizando-se de um texto, de barreiras físicas, e da imagem como barreira. Não era possível ter acesso ao local, e é aí de certa forma que a intervenção operava. Por essa razão, não foram divulgados horários de abertura, somente as datas do início e fim da intervenção, que se propôs ao mesmo tempo como uma possibilidade de pensar a imagem e sua constituição, a imagem e a (in)visibilidade nos dias atuais. Nessa ocasião, faziam parte do trabalho tanto o convite impresso, as imagens, a frase, o título da exposição, quanto a impossibilidade de entrar nesse espaço, a iminência de seu desaparecimento, o fato de que era um espaço dedicado à fotografia, à imagem.

Figura 3

A dúvida, FotoGaleria, Porto

Alegre, 2004. Vista da entrada da galeria. Lona vinílica, impressão com plotter de imagem fotográfica e texto. 
Figura 4

A dúvida, FotoGaleria, Porto Alegre, 2004. Convite (frente), off-set, $15 \times 15 \mathrm{~cm}$.

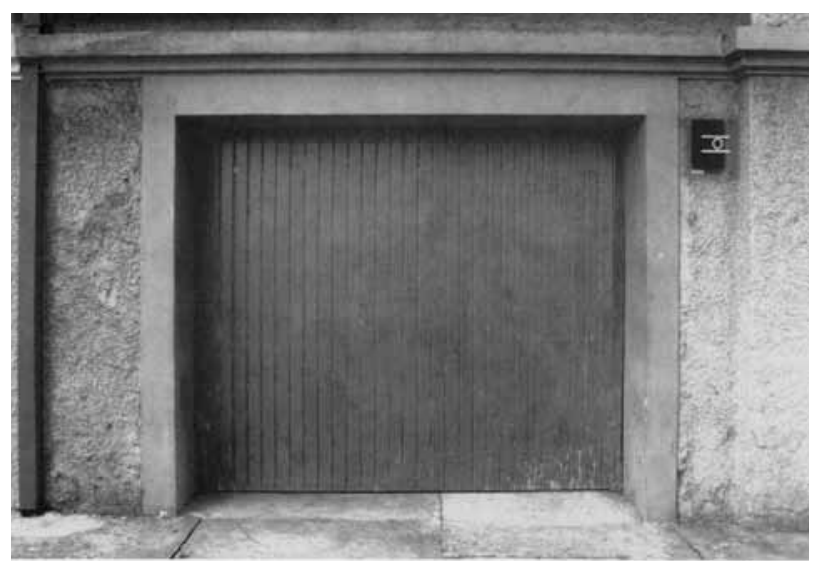

No verso do convite de $A$ Duvida estava escrito que se tratava de uma proposta de exposição. Chamei-a assim por que foi com a noção de proposta em mente que conversei com Fábio Del Re e Lucas Moura, à época os diretores da FotoGaleria. Foi essa noção que abriu para o diálogo e para um trabalho colaborativo, e impulsionou a elaboração da intervenção. A foto utilizada para o convite e para o plotter foi realizada por eles, e Paulo Silveira colaborou com o design gráfico do plotter. Ao mesmo tempo, foi o que se apresentou ao publico: uma proposição para o pensar e o agir.

\section{a dúvida \\ uma proposta de exposiçăo de Hélio Fervenza}

28 de agosto a 25 de setembro de 2004
Figura 5 A dúvida, FotoGaleria, Porto Alegre, 2004. Convite (verso), off-set, $15 \times 15 \mathrm{~cm}$. 
Embora pertencendo a contextos diferentes e implicando diferenças de métodos e motivações, podemos identificar no campo da arte outras exposições onde também foram utilizadas barreiras físicas e processos de ocultamento em sua realização e apresentação. É o caso, por exemplo, do grupo japonês Gutaï. Segundo a historiadora da arte Florence de Mèredieu, o grupo montou em 1956 "nas ruínas de um reservatório bombardeado, uma exposição invisível, fechada ao publico e perceptível somente por intermédio de fotografias" (DE MÈREDIEU, 1994, p.372).

Ainda no Japão, em maio de 1964 o grupo Hi Red Center esvaziou a galeria Naika em Tóquio, para o que chamaram de Evento-Fechamento (Closing Event). Este consistia no anuncio e na apresentação da Grande Exposição Panorama (Great Panorama Exhibition), acompanhada do fechamento da galeria. Conforme escreveu Reiko Tomii em texto sobre o grupo, no dia 12 desse mês eles "pregaram dois sarrafos em forma de $\mathrm{X}$ sobre a porta impedindo qualquer pessoa de entrar, e colocaram cartazes em inglês e em japonês que indicavam claramente: 'Fechado'. O convite da exposição - que com os outros elementos da exposição era parte integrante da operação sistemática de Hi Red Center - dizia: 'A galeria está fechada pelo Hi Red Center. Se você tem tempo livre, obrigado por não passar." (TOMII, 2009, p. 437). Cinco dias depois, no dia 16 de maio, o grupo retirou os sarrafos, reabriu a galeria e concluiu o evento oferecendo uma festa de fechamento, no lugar da tradicional vernissage de abertura de exposição.

Em principio, alguém que vai a uma exposição espera ver imagens ou objetos, pinturas, fotografias, obras de arte. Há um ver e uma expectativa de algo para ver em jogo. E os convites ao nos anunciarem uma exposição, deixam no ar essa espera. Assim, o artista norte-americano Robert Barry realiza entre 1969 e 1970 o que ele chamou de Closed Gallery Piece no qual três galerias publicaram convites anunciando uma exposição sua, e ao mesmo tempo, comunicando que nos períodos das diferentes mostras as galerias estariam fechadas. Barry realiza também entre 1972 e 1973 a Invitation Piece, no qual uma galeria convidava para uma exposição sua numa outra galeria situada numa outra cidade, a qual por sua vez publicava um convite para uma exposição numa outra e assim repetidamente, alternando os locais até retornar para a primeira galeria que havia anunciado a exposição. Em nenhum desses espaços e em nenhuma das datas marcadas havia obras de Barry para serem vistas. 
Levando ainda em conta as diferenças nas motivações e contextos, gostaria de aproximar dos trabalhos referidos, um fragmento da narrativa que se encontra no filme Sem Sol de Chris Marker, o qual aponta para um tipo bastante especial de sensibilidade:

"Quando a primavera vinha, e para anunciá-la o corvo gritava meio-tom acima, eu tomava o trem verde da Yamanote Line e descia na estação de Tóquio vizinha do Correio Central. Mesmo que a rua estivesse vazia eu parava no sinal vermelho, à japonesa, para deixar passar os espíritos dos carros quebrados. Mesmo que não esperasse nenhuma carta, eu parava diante da posta restante, porque devemos honrar as cartas rasgadas, e diante do guichê do correio aéreo, para saudar os espíritos das cartas não enviadas. Eu media a insuportável vaidade do ocidente, que sempre privilegiou o ser sobre o não-ser, o dito sobre o não-dito ${ }^{7 "}$.

Nos trabalhos antes mencionados, os quais são parte de um grupo bem maior de exemplos, vemos uma proximidade com o que escreve Florence De Mèredieu sobre o invisível em sua História Material \& Imaterial da Arte Moderna:

“Ora, trata-se a partir de agora, não somente de tornar visível o invisível, como desejava Klee, de materializar e encarnar sob uma forma palpável os dados imateriais, mas de integrar realmente a percepção do invisível, do impalpável e do imaterial no interior da obra plástica. Não é mais somente questão de transferência de uma ordem para outra, mas da pura apreensão de um imaterial. $\mathrm{O}$ novo então é a intrusão do não-visível, do não-tátil ou do não-perceptível no seio mesmo disso que possui nome de arte" (DE MÈREDIEU, 1994, p.372).

Retomando a abordagem da proposta de exposição $A$ dúvida, penso que ela pode também ser relacionada com minha pesquisa sobre o mostrar e o esconder realizada no início dos anos noventa (FERVENZA, 1995). Ela desenvolveu-se a partir da ideia de que o mostrar das obras não existe em si, mas que ele é relativo a um contrário ou a elementos que permanecem nãovisíveis. Os dois termos não sendo absolutos, mas provocando o movimento e o jogo de uma redefinição constante. Podemos atingir o não-visível a partir do visível. Mas o contrário é também verdadeiro. $\mathrm{O}$ visível e o não-visível encontram-se numa relação de reciprocidade, na qual eles geram-se mutuamente. 
Constatei que na arte moderna e contemporânea, vários artistas se confrontaram com o problema do mostrar (Tatlin, Ryman) e do esconder (Duchamp, Cildo Meireles, Antônio Manuel), ao abordá-los a partir da visibilidade, ou do não-visível na obra. Observei também que os artistas se preocuparam, por vezes em alternância, seja com o problema da apresentação das obras, seja com os fenômenos de ocultação, mas não na direção dos dois ao mesmo tempo, dentro da mesma obra.

Em graus diferentes e no âmbito operacional, a efetivação do mostrar e do esconder será questão de barreiras ou de transparências. A relação entre visível e não-visível mantêm-se igualmente dentro dessa abordagem. Certas obras agem como barreiras. Elas nos conduzem do visível de suas formas àquilo que nós não podemos atingir com o olhar. Outras incorporam as transparências dos materiais, dos processos. As barreiras poderão esconder isto que por um motivo ou outro, não está disponível ao olhar, mas elas podem ser também, o visível por excelência. Igualmente, a transparência pode permitir-nos de estender nossa visão, de ver através, e de tornar visíveis coisas, estruturas, noções ou situações. Mas pode acontecer que o invisível seja a transparência mesmo: "(...) o invisível não é obscuro nem misterioso, é transparente..." (PAZ, 2002, p. 9), dirá Octavio Paz no livro Marcel Duchamp ou o Castelo da Pureza.

O esconder não é somente questão de ocultação, como se poderia entender, no sentido de uma coisa debaixo de outra, ou de uma coisa atrás de outra, quer dizer, no sentido de uma interposição, de um recobrimento. O esconder é igualmente questão de vazio, de transparência.

A realização de um efeito de barreira ou de transparência dependerá do vazio e do cheio, do posicionamento dos elementos na relação (antes ou depois, diante ou atrás, etc.), ou de uma contextualização, face ao observador e àquilo que ele pode ou não atingir pelo olhar. $\mathrm{O}$ mostrar e o esconder dependem da posição do sujeito, no seu mais amplo sentido.

Mas, diferentemente dos trabalhos inicialmente referidos, como os do grupo Hi Red Center ou de Robert Barry, trata-se em $A$ dúvida da existência material de barreira ou de ocultamento, no qual foi utilizada especificamente uma imagem para sua elaboração, e com um efeito de invisibilidade. E neste ponto é importante lembrar que a imagem e seus sentidos encontravam-se aí implicados de uma maneira mais abrangente. Ao produzir uma barreira, um impedimento, uma ação do visível em direção do invisível, isto me permi- 
tia ao mesmo tempo pensar nesse distanciamento no qual se encontra envolvida toda imagem.

Assim, no livro "Pode a imagem matar?", escrito em reação aos acontecimentos do dia 11 de setembro de 2001, a filósofa Marie José Mondzain desenvolve uma série de reflexões sobre o que é uma imagem, e sua relação com a visibilidade, a violência, o poder, a mídia, o espetáculo... Para isso ela exercita uma análise constitutiva da imagem. Ela nos diz que:

"A imagem insustentável do mal é um tema recorrente em toda a Antiguidade, do olhar de Medusa ao espelho empregado por Teseu para vencê-la, passando pela fusão mortal de Narciso e de sua imagem. A história de Narciso nos fala da violência de um reflexo que mata. Esses mitos e suas lendas dizem uma mesma coisa: a imagem nos olha e pode nos devorar. Todos esses dispositivos de crença e de fabricação são fundados sobre a identificação. Tornar-se um com aquilo que vemos é mortal e o que salva, é sempre a produção de uma distância liberadora. Viver, curar, é afastar-se de toda fusão e pegar o mal na sua própria armadilha, a da identificação. A violência da imagem se desencadeia quando esta permite a identificação do infigurável no visível. O que quer dizer que a imagem só se sustenta na dissimilaridade, no intervalo entre o visível e o sujeito do olhar. Mas este intervalo é visível? Se fosse, ele não seria mais intervalo. Há então no ato de ver um 'gesto' invisível que constitui o intervalo do ver. Talvez ele seja constituído pela voz.” (MONDZAIN, 2002, p. 28-29).

Esse distanciamento do qual nos fala Marie José Mondzain, presente em nossa relação com as imagens, encontra-se em estado de perda hoje em dia. Muitas e sucessivas imagens vêm constante e sistematicamente preencher com sua visibilidade essa distância entre o sujeito e a imagem, expulsando o sentido que poderia nos trazer esse intervalo. Acompanhando-a em sua reflexão, temos muitas visibilidades, mas talvez, paradoxalmente, poucas imagens. A consideração dos aspectos levantados num processo de criação e de apresentação da imagem permite enfatizar a especificidade de sua intensidade. A arte pode nos auxiliar a pensá-la, incluindo a invisibilidade nesse pensamento.

\section{Referências}

DE MÈREDIEU, Florence. Histoire Matérielle E Immatérielle de l'Art Moderne. Paris: Bordas, 1994. 
FERVENZA, Hélio. Le Montrer et le Cacher dans le Rapport d'un Signe et de son Espace. Doutorado em Artes Plásticas. Paris: Université de Paris I - Panthéon Sorbonne, 1995. MONDZAIN, Marie José. L'image peut-elle tuer?. Paris: Bayard Éditions, 2002.

PAZ, Octavio. Marcel Duchamp ou o Castelo da Pureza. São Paulo: Editora Perspectiva, 2002.

TOMII, Reiko. Dissolution de l'exposition : Hi Red Center et Matsuzawa Yutaka. In: Vides-Une rétrospective. Paris: Centre Pompidou, 2009.

\section{NOTAS}

1. O presente trabalho foi realizado com apoio do CNPq, Conselho Nacional de Desenvolvimento Científico e Tecnológico - Brasil.

2. Este texto foi apresentado inicialmente no X Congresso Internacional da Associação de Pesquisadores em Crítica Genética, realizado em Porto Alegre no período de 22 a 25 de novembro de 2010, na Pontifícia Universidade Católica do Rio Grande do Sul / PUC - RS. Ele deverá ser publicado nos anais do congresso, o que não foi efetivado até o presente momento.

3. Disponível em: <http://www.heliofervenza.net/arquivo/proposicoes/aduvida/index.htm>. Acesso em: 05/12/2011.

4. Disponível em: <http://www.heliofervenza.net/arquivo/proposicoes/objetos_mentais/index.htm>. Acesso em: 05/12/2011.

5. Disponível em: <http://www.heliofervenza.net/arquivo/proposicoes/ pais_futuro/>. Acesso em: 05/12/2011.

6. Disponível em: <http://www.heliofervenza.net/arquivo/proposicoes/degelo/>. Acesso em: 05/12/2011.

7. MARKER, Chris. Sem Sol / La Jetée. Coleção Cinema Essencial, Aurora DVD, 2007.

Recebido em: 09/12/11

Aceito em: 27/02/12

\section{HÉLIO FERVENZA}

helioiv@adufrgs.ufrgs.br

Artista plástico. Doutorado em Artes Plásticas na Université de Paris I Panthéon-Sorbonne. Professor do Instituto de Artes da UFRGS em Porto Alegre, Departamento de Artes Visuais / Programa de Pós-Graduação em Artes Visuais, pesquisador do CNPq e coordenador do grupo de pesquisa Veículos da Arte. Desenvolve atividades, propostas e projetos artísticos diversos junto ao programa FPES - Perdidos no Espaço. Site: www.heliofervenza.net 

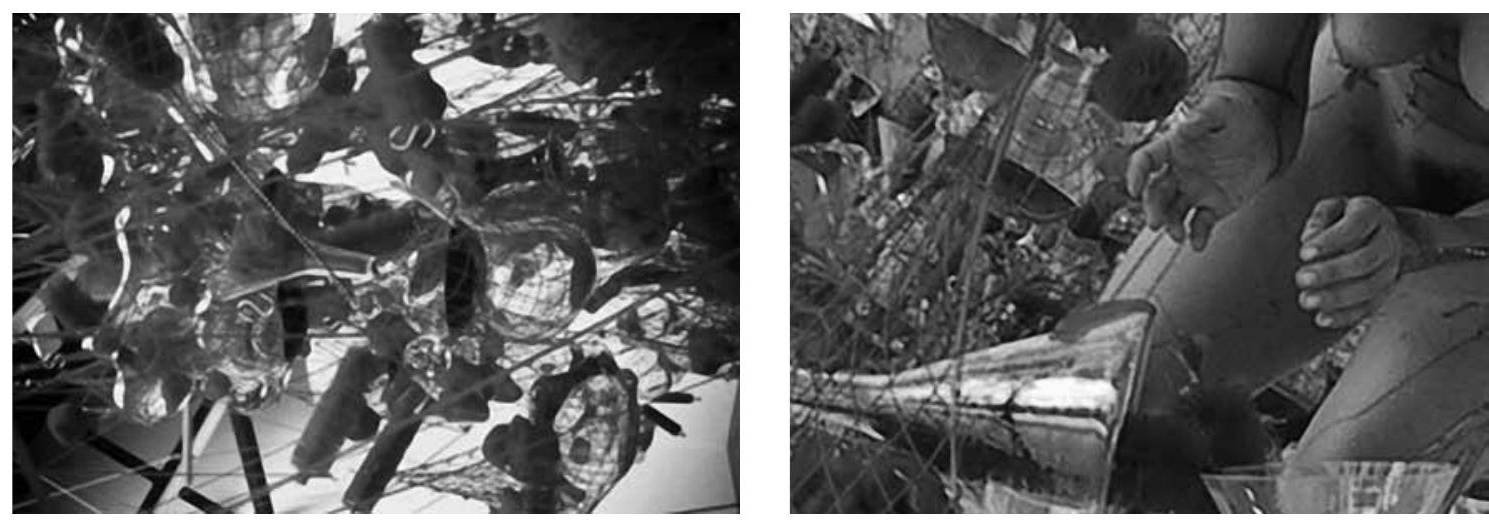